\author{
Marquette University \\ e-Publications@Marquette
}

Social and Cultural Sciences Faculty Research and Publications

$5-2016$

\title{
Hearing the Community: Evolution of a Nutrition and Physical Activity Program for African American Women to Improve Weight
}

\author{
David Nelson \\ Medical College of Wisconsin \\ Angelique Harris \\ Marquette University, angelique.harris@marquette.edu \\ Barbara Horner-lbler \\ Bread of Healing Clinic \\ Kimberly Salas-Harris \\ Marquette University \\ Edith Burns \\ Medical College of Wisconsin
}

Follow this and additional works at: https://epublications.marquette.edu/socs_fac

Part of the Social and Behavioral Sciences Commons

\section{Recommended Citation}

Nelson, David; Harris, Angelique; Horner-Ibler, Barbara; Salas-Harris, Kimberly; and Burns, Edith, "Hearing the Community: Evolution of a Nutrition and Physical Activity Program for African American Women to Improve Weight" (2016). Social and Cultural Sciences Faculty Research and Publications. 172.

https://epublications.marquette.edu/socs_fac/172 


\title{
Hearing the Community: Evolution of a Nutrition and Physical Activity Program for African American Women to Improve Weight
}

\author{
David Nelson, PhD, MS \\ Angelique Harris, $\mathrm{PhD}$ \\ Barbara Horner-Ibler, MD, M.Div, M.S.W. \\ Kimberly Salas Harris, MA \\ Edith Burns, MD
}

\begin{abstract}
Summary: Listening to the needs of the community is an important step toward reducing health disparities. Researchers may need to adjust their methods to maximize participation and benefit to the community. This report describes how the project team adjusted its approach to a weight loss intervention to support a community of African American women seeking to improve their health.
\end{abstract}

Key words: Community-engaged research, women, weight loss.

\section{Background}

$S^{i}$ ince 1980, the overall rate of obesity has tripled in the United States. ${ }^{1,2}$ Among all adults, the prevalence of obesity-Body Mass Index (BMI) in adults greater than $30^{3}$ - among African American women is higher than any other racial or ethnic subgroup. ${ }^{4}$ In 2011-2013, nearly 57\% of African American women were obese compared with $43 \%$ of Hispanic women, and $34 \%$ of White women. ${ }^{5}$ Higher rates of obesity, and its complications, follow the social gradient. ${ }^{6,7}$ Strategies to address obesity must be useful and relevant to individuals and communities in order to be effective and make a difference. Even under the best of circumstances and with intensive treatment, assisting individuals to meet and keep weight loss goals is a challenge. ${ }^{8,9}$ Individuals living in low socioeconomic status face additional structural challenges within the built environment by having limited nutrient-rich food choices and safe and affordable opportunities to engage in physical activity. ${ }^{10,11}$ As a result of these challenges, soliciting greater input

\footnotetext{
DAVID NELSON is an Associate Professor for the Department of Family and Community Medicine Medical College of Wisconsin. ANGELIQUE HARRIS is the Director, at the Center for Gender and Sexualities Studies and an Associate Professor for the Department of Social and Cultural Sciences at Marquette University. BARBARA HORNER-IBLER is the Medical Director for the Bread of Healing Clinic. KIMBERLY SALAS HARRIS is an Associate Director at the Health Careers Opportunity Program at Marquette University. EDITH BURNS is a Professor for the Department of Medicine, Medical College of Wisconsin. Please send all correspondence to David Nelson, 8701 Watertown Plank Road, Milwaukee, WI. 53226. Phone: 414-955-4386. Email: danelson@mcw.edu.
} 
from community members may increase the likelihood of success with individual and community-level interventions.

Within the context of public health, community-based participatory research (CBPR) is supported through partnerships. Within this paradigm, community-based organizations, academic researchers and community members come together to identify common issues related to the health of the community and to agree upon interventions. ${ }^{12}$ Each partner provides a unique but complementary perspective not only to understand, but to resolve the health-related or social issue. Such an alignment to research is based upon the principles of equity and bi-directional learning and presupposes an iterative process. ${ }^{12}$ Community-based participatory research is not a singular method but an orientation to the research process. As such, integrating community health advocates in the research and utilizing a common sense model (i.e., eliciting perceptions of illness based on prior experiences and interpretation of symptoms) to understand community health issues fits well within the tenets of CBPR. Despite a sound rationale for utilizing $\mathrm{CBPR}$, little is written about the need to make adjustments during the research process as determined by community-identified needs. This Report from the Field describes how one community-academic partnership adjusted its processes to meet the needs of African American women through a church-based CBPR program in Milwaukee, Wisconsin.

\section{Context}

Milwaukee is the largest and most ethnically diverse city in Wisconsin, with a population of over $600,000 .{ }^{13}$ While the number of Whites that live in the city has steadily decreased over the census years 1980, 1990, and 2000 African American, Hispanic, and Asian populations have increased. ${ }^{14}$ Though the highest concentration of health resources exists within the city, health disparities are most apparent in many of these areas. According to the Milwaukee Health Report, ${ }^{15}$ individuals who live in ZIP codes classified as low socioeconomic status (SES) have worse health outcomes than those living in areas categorized as middle or high SES. As a result, Milwaukee County ranks worse than all but one county in the state for overall health outcomes. ${ }^{15}$

In an attempt to address these disparities, an endowment was created from the 2004 conversion of the Blue Cross Blue Shield United of Wisconsin from not-for-profit to a for-profit entity. This entity, Advancing a Healthier Wisconsin, contains a grant component titled the "Healthier Wisconsin Partnership Program" (HWPP). ${ }^{16}$ The aim of this program is to improve the health of the state's population through community and academic partnerships with the Medical College of Wisconsin (MCW). New partnerships, as well as previously and currently funded community-MCW academic partnerships, were eligible to apply for Development Awards for up to two years or Impact Awards for up to five years. Development Award projects are designed to build partnership synergy, develop pilot projects and to create strategic action plans between community and academic partners.

In 2012, the Bread of Healing Clinic (BOH) and the Marquette Clinic for Women and Children (MCWC) (both located in the basement of Cross Lutheran Church) collaborated with researchers from the Medical College of Wisconsin to write an HWPP 
Developmental Award to fund an intervention that focused on obesity among African American women. Both of these clinics serve uninsured individuals at no charge within a neighborhood called Lindsay Heights. Lindsay Heights is made up of a 100-square block area with approximately 2,200 households; 95\% of the residents are African American. Lindsay Heights experiences a poverty rate double that, and an average household income half that of the rest of Milwaukee. ${ }^{17}$ In this community, poverty is so pervasive that nearly $90 \%$ of single parents with two or more children have an income less than $185 \%$ of the federal poverty level. ${ }^{18}$ The team chose to work with African American adult women after a clinic chart review of $\mathrm{BOH}$ and MCWC determined that $51 \%$ of the women were obese, compared with $29.8 \%$ of women statewide. ${ }^{19}$ In addition, a high prevalence of hypertension (60\%) and type 2 diabetes (30\%) existed among the female clinic patients, considerably higher than the $32.3 \%$, and $8.2 \%$ rates seen for all adults in the state of Wisconsin.

\section{Initial Model}

The initial intervention design proposed randomizing participants to an immediate intervention group or to a wait list (control group). Baseline assessments would include body mass index (measured by weight and height), self-reported nutritional intake, and physical activity along with symptoms and signs of comorbidities associated with excess body weight. The primary objective of the study was to modify lifestyle behaviors to achieve a goal of eventual weight loss. That is, increased physical activity and consumption of healthy foods would result in the women achieving (or moving toward) "normal" weight status through a reduction of their BMI. After the initial assessment, following the protocol, measures would be repeated every three months for a maximum of 12 months. In line with a CBPR model, the team decided to use community health advocates (CHA) who would first receive training in, and then use Motivational Interviewing (MI) to initiate behavior change (based on the theoretical model of behavior change as described by DeClemente and Prochaska ${ }^{20}$ and Prochaska ${ }^{21}$ ). Finally, the team would seek input from the community, first in the form of focus groups prior to beginning the intervention, and then through a project advisory board (PAB) to be consulted throughout the course of the project. This was viewed as an important component since some members of the PAB and the CHA lived in the same community as the participants. The $\mathrm{PAB}$ would review project direction and design and inform the team if their approach was consistent with the cultural and social environment of the community. The project was submitted to and approved by the Internal Review Board at the Medical College of Wisconsin. Through word of mouth, flyers and referrals, over 60 women from the Lindsay Heights neighborhood were ultimately recruited to participate in the program.

\section{Focus Groups}

In addition to chart reviews and prior to implementing the initial protocol, women were recruited from the community to participate in six focus groups and discuss issues related to obesity and the proposed intervention. A total of 22 women responded to 
the flyers, signed informed consents and attended at least one of the six focus groups. Focus groups were convened twice per month with each meeting framed around a different topic related to obesity. Topics included body image, community resources, family, and the influence of obesity on the community, and in particular, its impact upon women. Results from the focus groups provided additional insight into three key areas that need to be recognized as the project moved forward. Insights include: 1) engagement of the community, 2) incorporating Common Sense Perceptions into weight reduction and 3) reliance upon community health advocates who provide social and educational support to participants.

\section{Moving Forward}

Efforts to engage the community in research must be based on foundational principles of CBPR such as trust, shared power, dialogue, capacity building and collaborative inquiry. ${ }^{22}$ From the start of the project, promotion of healthy body weight remained the goal. However, based upon input from the focus groups and the PAB, and improved understanding on the part of the research team, adjustments to the project were made to emphasize healthy lifestyle choices, rather than weight loss. For example, the focus group discussions brought to light a lot of ambiguity around the topic of obesity that was subsequently validated by the PAB. Instead, the community identified an "unhealthy lifestyle" as their main health concern. The participants also reminded the team that environmental factors, including a lack of access to stores that sell healthy food, was an important issue. The women indicated that home-cooked meals were not a regular occurrence in the community and many families ate meals prepared at fast-food restaurants. Finally, as one participant explained, "BMI [body mass index] does not tell the whole story" and "BMI does not reflect how I feel." This type of commonsense perception (reliance on personal, subjective symptoms as indicators of health status) provided the basis for an adjusted approach to work with African American women to promote healthy weight in this neighborhood, and yet still followed principles of CBPR.

What we came to call our Common Sense approach was designed not only to understand the perspective of the targeted community but also to guide the development of the intervention. The Common Sense Model (CSM) provides a framework to understand the perceptions of how an individual represents and comes to understand a health issue. Within the model, individuals look for a label or identity to explain a symptom or health issue regardless of whether or not that description is bio-medically correct. ${ }^{23} \mathrm{~A}$ key feature of CSM is its approach to fear and threat in relation to behavior change. ${ }^{24}$ The threat of a potential health concern does not provide sufficient motivation for behavior change. To facilitate change, individuals need knowledge and information on how to reduce the threat. Without such information, they have difficulty formulating an action plan and so tend to ignore or discount the fear.

An illustration of relevant cognitive processes and perceptions was provided by women during the focus groups that addressed body image, when they indicated that the terms "body mass index" or "BMI" and "obesity" have little relevance to them and those in their neighborhoods. The women did not express fear over an elevated BMI 
and thus saw no reason to lose weight. Although obesity is linked to chronic illness such as hypertension and type 2 diabetes $^{25}$ the development of these conditions is often asymptomatic, thus providing no direct, somatic experience to link overweight to the chronic condition. However, the women in the group did express that obesity had a direct effect on their ability to move around and be physically active. They thus expressed an interest in weight loss if it meant having more time and energy to spend with their families. Therefore, when their perceptions of the issue and personal experience matched the needs in their lives, the women were more open to weight loss as a means to an end. At the same time, and on the opposite end of the spectrum, these women associated lower BMI with ill health, in that women who lost weight either had "cancer" or were "on the pipe" (drug use), again reflecting the CSM of personal experience providing links between health and outcomes. The team also needed to consider the cultural implications of a higher BMI, which included the perception of "curvy" women as attractive, as well as the pride one takes in a well-fed family. Women in this group did not associate overweight with the threat of diabetes, hypertension, and heart disease. The community expressed considerable ambivalence in that excessive body weight was simultaneously a desirable attribute and a source of health problems. The project team seized upon this ambivalence as an opportunity to emphasize motivational interviewing as part of the intervention (MI) to address the health issue of obesity through the common-sense ideas of increased physical activity and healthy nutrition intake instead of focusing on the outcome of weight reduction.

Another part of the common-sense approach generated by community members was the decision to use community health advocates (CHA) as an important component of the intervention. The importance of CHAs to the success of the project was not completely realized until after the actual intervention began. Community health advocates are members of the target community who serve as champions to promote the welfare of their community and peers. As part of the intervention, CHAs work with participants to set individual goals for physical activity, diet and to develop an action plan based upon the individual's ability to access resources and achieve those goals. While working with the members of the community, CHAs found themselves in the roles of confidant and emotional supporters for the participants. Instead of developing a nutrition plan for the week, CHAs often found the participants needed to discuss issues of stress and depression and how to manage large and extended families with limited economic resources. Community health advocates also developed skills to set appropriate boundaries around signs of depression, and in time management as consultation sessions often took longer than expected due to these emotionally-laden social issues.

In summary, the original goal of this project was to use a community-academic partnership to engage in a CBPR model and develop an intervention to achieve appropriate weight loss for participants. Through interaction with the community, the team learned that medical constructs such as "obesity," "BMI," and "exercise capacity" had little relevance in the lives of the target participants. Instead, a more common-sense approach was needed to make the core components of the project relevant in the lives of participants. The use of focus groups, a project advisory board and community health 
advocates resulted in a program tailored to the perceptions of the participants while retaining its original goal of changing behaviors that cause and sustain obesity. This common-sense approach modified the focus of the project from emphasizing weight loss to focusing on increasing physical activity and healthy nutrition, and by addressing other related health issues in the community. Community health advocates not only focused on increasing physical activity and heathier nutrition but also expanded their roles as confidants to provide support for those individuals that struggled with stress and depression. This revised approach to the issue of obesity is anticipated to result in an intervention program that will improve outcomes that are relevant to the target community.

\section{References}

1. Ogden CL, Yanovski SZ, Carroll MD, et al. The epidemiology of obesity. Gastroenterology. 2007 May;132(6):2087-2102.

http://dx.doi.org/10.1053/j.gastro.2007.03.052

PMid:17498505

2. Ogden CL, Carroll MD, Flegal AR. Prevalence of obesity in the United States, 2009-2010. NCHS Data Brief. 2012 Jan;(82):1-8.

3. Centers for Disease Control and Prevention (CDC). Defining adult overweight and obesity. Atlanta, GA: CDC, 2012. Available at: http://www.cdc.gov/obesity/adult /defining.html.

4. U.S. Department of Health and Human Services. Obesity and African Americans. Rockville, MD: U.S. Department of Health and Human Services, 2013. http://minority health.hhs.gov/omh/browse.aspx?lvl=4\&lvlid=25.

5. Ogden CL, Carroll MD, Kit BK, Flegal KM. Prevalence of childhood and adult obesity in the United States, 2011-2012. JAMA. 2014 Feb 26;311(8):806-14.

http://dx.doi.org/10.1001/jama.2014.732

PMid:24570244

6. World Health Organization (WHO). Closing the gap in a generation: health equity through action on the social determinants of health. Geneva, Switzerland: WHO, 2008. Available at: http://apps.who.int/iris/bitstream/10665/43943/1/9789241563703_eng .pdf.

7. Wilkinson R, Marmot M, eds. Social determinants of health: the solid facts (2nd ed.). Geneva, Switzerland: WHO, 2003. Available at: http://www.euro.who.int/_data /assets/pdf_file/0005/98438/e81384.pdf.

8. Yanovski SZ, Yanovski JA. Long-term drug treatment for obesity: a systematic and clinical review. JAMA. 2014 Jan 1;311(1):74--86.

http://dx.doi.org/10.1001/jama.2013.281361

PMid:24231879 PMCid:PMC3928674

9. Kushner RF, Ryan DH. Assessment and lifestyle management of patients with obesity: clinical recommendations from systematic reviews. JAMA. 2014 Sep 3;312(9):943-52. http://dx.doi.org/10.1001/jama.2014.10432

PMid:25182103

10. Yancey A. Social ecological influences on obesity control: instigating problems and informing potential solutions. Obesity Management. 2007 Apr: 74-9.

http://dx.doi.org/10.1089/obe.2007.0020 
11. Kumanyika S, Grier SA. Targeting interventions for ethnic minority and low-income populations. Future Child. 2006 Spring;16(1):187-207.

http://dx.doi.org/10.1353/foc.2006.0005

PMid:16532664

12. Israel BA, Schulz AJ, Parker EA, et al. Review of community-based research: assessing partnership approaches to improve public health. Annu Rev Public Health. 1998;19:173-202.

http://dx.doi.org/10.1146/annurev.publhealth.19.1.173

PMid:9611617

13. U.S. Census Bureau. State \& Country Quick Facts. Washington, DC: U.S. Census Bureau, 2012. http://quickfacts.census.gov/qfd/states/00000.html.

14. Department of City Development. Citywide policy plan. Milwaukee, WI: Department of City Development, 2010. Available at: http://city.milwaukee.gov/ImageLibrary /Groups/cityDCD/planning/plans/Citywide/plan/CitywideExecSum.pdf.

15. Chen HY, Baumgardner DJ, Galvao LW, et al. Milwaukee Health Report: health disparities in Milwaukee by socioeconomic status. Milwaukee, WI: Center for Urban Population Health, 2011. Available at: http://www.cuph.org/milwaukee-health-report .html.

16. Medical College of Wisconsin. Advancing a healthier Wisconsin endowmwnt. Milwaukee, WI, 2012. Available at: http://www.mcw.edu/Advancing-Healthier-WI -Endowment.htm.

17. Zilber Family Foundation. Lindsay Heights: quality of life plan highlights. Milwaukee, WI: Zilber Family Foundation, 2010. Available at: http://www.zilberfamilyfoundation .org/pdfs/lindsay_heights/ZNI_QLP_Full_LindsayHts.pdf.

18. University of Wisconsin- Milwaukee. Socio-economic analysis of neighborhood issues facing Milwaukee Public Schools students and their families in zip code 53205. Milwaukee, WI: 2009. https://www4.uwm.edu/eti/2009/Report53205.pdf.

19. Trust for America's Health. The state of obesity in Wisconsin. Washington, DC: Trust for America's Health, Robert Wood Johnson Foundation, 2014. Available at: http:// stateofobesity.org/states/wi/.

20. DiClemente CC, Prochaska JO, Fairhurst SK, et al. The process of smoking cessation: an analysis of precontemplation, contemplation, and preparation stages of change. J Consult Clin Psychol. 1991 Apr;59(2):295-304.

http://dx.doi.org/10.1037/0022-006X.59.2.295 PMid:2030191

21. Prochaska JO. Decision making in the trantheoretial model of behavior change. Med Decis Making. 2008 Nov-Dec;28(6):845-9. Epub 2008 Nov 17.

http://dx.doi.org/10.1177/0272989X08327068

PMid:19015286

22. Minkler M, Wallerstein N. Introduction to community based participatory research. In: Minkler M, Wallerstein N, eds. Community-based participatory research for health: from process to outcomes (2nd ed.). San Francisco, CA: Jossey-Bass, 2003. PMCid:PMC1447939

23. Hale ED, Treharne GJ, Kitas GD. The common-sense model of self-regulation of health and illness: how can we use it to understand and respond to our patients' needs? Rheumatology (Oxford). 2007 Jun;46(6):904-6. http://dx.doi.org/10.1093/rheumatology/kem060 PMid:17449488 
24. Leventhal H, Singer R, Jones S. Effect of fear and specificity of recommendation upon attitudes and behavior. J Pers Soc Psychol. 1965 Jul;2:20-9.

http://dx.doi.org/10.1037/h0022089

PMid:14313839

25. Must A, Spadano J, Coakley EH, et al. The disease burden associated with overweight and obesity. JAMA. 1999 Oct 27;282(16):1523-9.

http://dx.doi.org/10.1001/jama.282.16.1523

PMid:10546691 